\begin{tabular}{|c|c|c|}
\hline $\begin{array}{l}\text { INFCGAIN } \\
P \cup B L I C A T I O N\end{array}$ & $\begin{array}{l}\text { International Journal of Advanced Engineering, Management and Science } \\
\text { (IJAEMS) } \\
\text { ISSN: 2454-1311 } \\
\text { Vol-7, Issue-3; Mar, } 2021 \\
\text { Journal Home Page Available: } \underline{\text { https://ijaems.com/ }} \\
\text { Journal DOI: https://dx.doi.org/10.22161/ijaems } \\
\text { Article DOI: } \text { https://dx.doi.org/10.22161/ijaems.73.7 }\end{array}$ & (1) \\
\hline
\end{tabular}

\title{
Modelling and Optimal Viscometry Formulation Evaluation of a Modified Green Based Self-Healing Automotive Paint
}

\author{
C. C. Okoye*, O. D. Onukwuli, M. I. Ejimofor and C. F. Okey-Onyesolu
}

Department of Chemical Engineering, Nnamdi Azikiwe Unviersity, Awka, Anambra State, Nigeria

*Email of Corresponding author: cc.okoye@unizik.edu.ng

Received: 03 Nov 2020; Received in revised form: 12 Jan 2021; Accepted: 03 Feb 2021; Available online: 17 Mar 2021

(C)2021 The Author(s). Published by Infogain Publication. This is an open access article under the CC BY license

(https://creativecommons.org/licenses/by/4.0/).

\begin{abstract}
This research successfully converted periwinkle shells, an agrowaste of regenerative resource, to an additive for the formulation of a self-healing car paint. The periwinkle shell was deproteinized, demineralised and deacetylyzed to produce chitosan. The parent chitosan sample in a series of reactions was modified by graft copolymerization with maleic anhydride and methyl methacrylate to yield a chitosan derivate (chitosan-g-maleic anhydride-g-(methyl methacrylate) copolymer (modified chitosan). A $2^{4}$ full factorial central composite rotatable experimental design and a three-layered (4:n:1) feed-forward architecture of artificial neural network trained by the Levenberg-Marquardt backpropagation algorithm was employed to model and predict the process variables. The physicochemical properties of the paint formulations were studied using standard methods. Fourier Transform Infrared was used to identify the functional groups of the samples under investigation. Grafting efficiency (GE \%) of $75.3 \%$ and grafting yield $(G \%)$ of $76.25 \%$ indicates effective graft copolymerization of methyl methacrylate on to the maleilated chitosan. The functional groups revealed by the FTIR spectra confirmed the graft copolymerization of maleilated chitosan with methyl methacrylate to yield a chitosan derivate (chitosan-gmaleic anhydride-g-(methyl methacrylate) copolymer and also identified the presence of the modified chitosan in the self healing paint. The drying time, adhesion and chemical resistance properties measured were within acceptable limits. ANOVA results show that quadratic equation best describes the viscometry behaviour of the paint formulation. The binder and solvent showed significant effect on the response. The $A A D(\%)$ and coefficient of determination values obtained for RSM and ANN show that the two techniques predicted to a great extent the viscometry behaviour of the system, however, ANN model marginally outperformed the RSM model. An optimal response of $99.85 \mathrm{mPa} . \mathrm{s}$ was recorded at $70.24 \mathrm{~g}$ binder, $79.99 \mathrm{~g}$ solvent, $15.72 \mathrm{~g}$ pigment and $3 \mathrm{~g}$ additives.
\end{abstract}

Keywords - viscosity, graft co-polymerization, self-healing paint, RSM, ANN.

\section{INTRODUCTION}

A coating is a covering that is applied to the surface of an object, the purpose of application may be to improve surface appearance, adhesion, corrosion resistance, wear resistance and scratch resistance. An industrial coating is a paint or coating defined by its protective, rather than its aesthetic properties, although it can provide both. Paint is basically composed of four materials: resin (binder), solvent, pigment(s) and additives, homogeneously mixed together which when applied on a surface as a thin layer forms a solid dry adherent film after oxidation/ evaporation/ polymerization. According to Rodger (2008), the basis for paint classification is usually based on its purpose and area of application. A water base paint is term 
as an emulsion paint which can be applied for architectural building (Michael, 2005; Rodger, 2008) while a paint whose diluent of formulation and medium of cleanliness is solvent is referred to as gloss paint. This type of paint can be formulated for refinery equipment coating, road marking purposes, varnishes, car surface coating and so on. (Rodger, 2008; Alirezaet al., 2009).

At the beginning of the automotive industry about 100 years ago, cars were painted with a varnish-like product that was brushed onto the vehicle surfaces; this coating was sanded and smoothed, and then the varnish was reapplied and refinished to establish several layers of the coating (Akafuah et al., 2016). The durability of enamel finishes was improved considerably by the 1960s with the introduction of acrylic stoving enamels (Learner, 2000). To further improve coatings' appearance and durability, a new type of wet-on-wet finish was developed and introduced in the late 1970s, consisting of a thin basecoat and a thicker clearcoat (Fettis, 2008). Another significant enhancement in paint technology was the development of "alkyd" enamel paints that were introduced on some car models in the early 1930s (Standeven, 2006). Automotive coatings continue to evolve as they either satisfy or are anticipated to meet customer expectations and environmental regulations while also lowering manufacturing and ownership costs. One of these evolutions is in the use of smart coatings because they offer the potential to significantly improve surface durability while adding additional functionalities or properties like super-hydrophobicity, self-stratifying, selfsensing, sound proofing, vibration damping and selfhealing (Akafuah et al., 2016).

Self-healing materials offer a new route toward safer, longer-lasting products and components (Gianluca and Salvatore, 2016). Self-healing effect is generally defined as the recovery of coating integrity after some kind of damage occurs (Carneiro et al., 2012) using the resources inherently available to them (Jamil et al., 2015). Selfhealing materials address this degradation through the inclusion of an active phase that responds to the micro damage by initiating a repair mechanism. One of the selfhealing materials which has been investigated in polymer technology is chitosan(Husnugul et al., 2013). The chitosan structure is presented in plate 1 (Younes and Rinaudo, 2015).

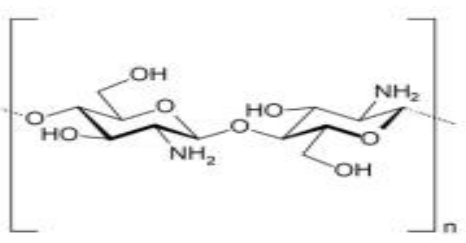

Plate 1: Chitosan Structure
Chitosan is one of the most promising polysaccharides due to its unique physicochemical properties namely biocompatibility, biodegradability (Ahmed and Ikram, 2016), antimicrobial activity and excellent film-forming ability, which have attracted scientific and industrial interest. Chitosan is very economical and can be generated almost from nothing. The parent chitosan sample produced has limited solubility in organic solvents (Chen et al., 2011), therefore, for best performance in the paint matrix there is need for chemical modification. Chitosan was modified by graft co-polymerization process to yield chitosan-g-maleic anhydride-g-(methyl methacrylate). The used of maleic anhydride (MA) gives notable importance in the drying properties, hardness and colour of the resin (Lohbeck and Haferkorn, 2000). It is often used to effectively increase the viscosity of a resin which will then require a large volume of dilution solvent, thus reducing the cost of the alkyd.

Nigeria is one of the countries blessed with innumerable untapped materials of regenerative resources which could be transformed into useful materials thus possibly contributing toward waste minimization. There is a clarion call for a paradigm shift on re-processing of residuals and wastes for sustainability and improvement on the aesthetics of our environments. In line with this, periwinkle shell, an agrowaste of regenerative resources was utilized in generating a modified biopolymeric material which acts as an additive for the formulation of self healing car paint.

Painting process for automotive industries is very important to give a more attractive appearance to the vehicles and to provide a layer of protection for the body against corrosion and weathering. It is one of the major costs in car manufacturing, it may cost more expensive than the body itself. Maybe the high costs are in terms of the processes that occur in painting process and not the price of the machines that are used in the paint shop (Jamaluddin, 2015).

Viscosity is an important parameter to be considered in paint application on surfaces. Spray guns will not atomize effectively when used with highly viscous paints. At extreme cases, the paint will not be ejected from the spray gun's orifice. Poorly atomized coatings result in a rough surface, poor appearance and significantly reduced coverage. However, proper viscosity of paint will atomize a fine mist and leave tiny droplets on the desired spraying surface. These tiny droplets will then flow together and make a smooth and level film (Jamaluddin, 2015). Experimental process design is key to establishing experimental conditions to achieve target viscosity for effective paint application. 
Experimental process design is a systematic method to determine the relationship between factors affecting a process and the output of that process (Asfaram et al., 2017). The overall influence of the combined possible interactions of the significant factors: binder, solvent, pigment and additives on the viscosity of the self healing paint will be investigated using a $2^{4}$ full factorial experimental process design. Based on the experimental results, a mathematical model will be developed using the Response surface methodology (RSM) to describe the viscometry behaviour of the paint formation within the design space. Also an artificial intelligence method, the artificial neural network, which has gained prominence in many disciplines including engineering will be adopted as an effective tool to predict the process parameters. ANN has universal approximation capability, i.e. it can approximate almost all kinds of non-linear functions including quadratic functions, whereas RSM is useful only for quadratic approximations (Desai et al., 2008).

The effective application (spraying and brushing) of all types of paint greatly depends on viscosity thus this research aims at modeling the viscometry response for a self-healing car paint formulation. To the best of our knowledge, there is no published optimal factor evaluation data for a modified biopolymeric material developed from periwinkle, an agrowaste, as an additive for the production of a self healing car paint. Results obtained from error analyses (absolute average deviation (AAD (\%) and $\mathrm{R}^{2}$ ) computations were used to compare the predictive capability of the RSM and ANN generated models in capturing the viscometry responses for interaction of the input controllable variables.

\section{MATERIALS AND METHODS}

\section{Materials}

The precursor for the modified biopolymeric material preparation was sourced from an agrowaste, periwinkle shells indiscriminately disposed in our environment. Binder (alkyd resin (BN 2814520)) and additives (mixdrier and anti-skin) were sourced from Intecil industries Ltd, Enugu and Hazel Chemical Company, Enugu respectively, solvent (white spirit) and pigment (titanium (IV) oxide) were purchased from a chemical vendor at Bridge Head Chemical market Onitsha, Nigeria. All chemicals used for the experimental procedures were of analytical grade and used without further purification.

\section{Methods}

\section{Preparation of Chitin and Chitosan}

Deproteinization
The periwinkle shells were pulverised into powder using a dry grinder and sieved with $2 \mathrm{~mm}$ sieve. $50 \mathrm{~g}$ of the less than $2 \mathrm{~mm}$ size powdered periwinkle shell was weighed into a $500 \mathrm{ml}$ beaker and $200 \mathrm{ml}$ of $4 \%$ (w/v) $\mathrm{KOH}$ was added with constant stirring for $6 \mathrm{~h}$ at $80^{\circ} \mathrm{C}$ and filtered. The residue was washed with distilled water until it is free of base and then dried at $100^{\circ} \mathrm{C}$ for $2 \mathrm{~h}$ (Okoya et al., 2014).

\section{Demineralization}

The deproteinized periwinkle shell residue was poured into a $250 \mathrm{ml}$ conical flask and $100 \mathrm{ml}$ of $3 \%$ (v/v) $1 \mathrm{M}$ $\mathrm{HCl}$ was added and placed on a magnetic stirrer for $3 \mathrm{~h}$ at $30^{\circ} \mathrm{C}$ to demineralise it. The content was filtered and the residue washed until it is free of acid. The acid free residue was then dried at $90^{\circ} \mathrm{C}$ for $1 \mathrm{~h}$. A snow white residue called chitin was obtained (Okoya et al., 2014).

\section{Deacetylation}

The chitin was poured into a $250 \mathrm{ml}$ conical flask for deacetylation, $50 \%$ (w/v) $\mathrm{NaOH}$ solution was added, stirred at $30^{\circ} \mathrm{C}$ for $4 \mathrm{~h}$ and filtered. After filtration, the residue, chitosan was washed until the filtrate is neutral and dried at $90^{\circ} \mathrm{C}$ for $1 \mathrm{~h}$, then store for studies (Okoya et al., 2014).

Preparation of chitosan -g-maleic anhydride -g(Methylmethacrylate) co-polymer

\section{Preparation of chitosan- g- Maleic anhydride}

Chitosan $(2 \mathrm{~g})$ and maleic anhydride $(6 \mathrm{~g})$ were dissolved in $100 \mathrm{ml}$ of dimethyl formamide (DMF), and then the mixture was stirred at $130^{\circ} \mathrm{C}$ for $3 \mathrm{hrs}$ under nitrogen atmosphere. The resultant solution was cooled to room temperature and poured in to ice water to precipitate the product. The product was collected by filtration, washed with diethyl ether for three times and then dried in vacuum at $40^{\circ} \mathrm{C}$. The grayish white powder of $\mathrm{N}$-maleilated chitosan was obtained. (Hemalatha and Sudha, 2011).

\section{Chitosan-g-maleic anhydride-g-(Methyl methacrylate)}

The graft co-polymer was homogeneously synthesized in aqueous solution by using ceric ammonium sulphate as initiator. A mixture of $0.5 \mathrm{~g}$ of maleilated chitosan and $1.6 \mathrm{~g}$ CAS/10ml of $\mathrm{HNO}_{3}$ was stirred followed by the addition of methacrylate $(2 \mathrm{~g})$. The reaction was performed at $70^{\circ} \mathrm{C}$ for $1 \mathrm{hr}$. The contents of the flask were cooled to room temperature and poured into $10 \% \mathrm{NaOH}$ solution to precipitate the graft co-polymer. The grafting efficiency (GE \%) and grafting yield (G \%) were calculated as follows (Hemalatha and Sudha, 2011):

$$
G E \%=\frac{w_{g}}{w_{g}+w_{i}} \times 100
$$




$$
\mathrm{G} \%=\frac{\mathrm{W}_{\mathrm{g}}}{\mathrm{W}_{\mathrm{a}}} \times 100
$$

Where,

$\mathrm{Wa}=$ Weight of monomer.

$\mathrm{Wi}=$ Weight of chitosan - g-Maleic anhydride.

$\mathrm{Wg}=$ Weight of N-Maleilated chitosan-g-(Methyl methacrylate).

\section{Characterization}

\section{FTIR}

Buck scientific M530 USA FTIR was used for the analysis. This instrument was equipped with a detector of deuteratedtriglycinesulphate and beam splitter of potassium bromide. The software of the Gram A1 was used to obtain the spectra and to manipulate them. An approximately of $1.0 \mathrm{~g}$ of samples, $0.5 \mathrm{ml}$ of nujol was added, they were mixed properly and placed on the salt pellet. During measurement, FTIR spectra was obtained at frequency regions of 4,000-600 $\mathrm{cm}^{-1}$ and co-added at 32 scans and at $4 \mathrm{~cm}-1$ resolution. FTIR spectra were displayed as transmitter values (Van der et al., 2004).

\section{Drying time}

A whatman filter paper was placed unto a panel under investigation after 4 hours of application. A rubber band was placed unto the filter paper with the smaller diameter downwards. A $50 \mathrm{~g}$ brass was placed on the rubber band and left for 1 minute. The weight and rubber band were removed and then the panel inverted. The filter paper should fall off the test film (if necessary with a light tap) to obtain the tack free time (NIS 574: 2008).

\section{Adhesion}

A multi-blade cutting tool was used to cross-hash the substrate. A soft tissue was used to clean the surface to remove any detached flakes or ribbons of coating. An adhesive tape was then firmly placed on the cut area to ensure good contact. The adhesive tape was forcefully pulled out of the scratched area and examined whether the coated paint peeled off along with the tape.

\section{Chemical resistance}

A mixture of acetone, demineralized water and isopropyl alcohol were dropped randomly on the coated surfaces of the formulations and kept at room temperature for 24 hours according to ASTM D1308 test method. The samples were observed to determine if there are stains that can result to corrosion or reducing the life span of the coated substrates.

\section{Viscosity}

The viscosities of the paint formulations were measured with a Digital Viscometer (NDJ-5S) using spindle 3 with a speed of $60 \mathrm{rpm}$ at $29 \pm 1^{\circ} \mathrm{C}$. The viscometer spindle was dipped into the paint sample in a beaker, the minimum insertion point on the spindle was ensured which was followed by viscosity measurement.

\section{Experimental design}

The controllable input variables and the response variable was modeled using the response surface methodology (RSM) technique. A central composite design (CCD) was selected to determine the experimental conditions as the inclusion of axial experimental points allow for a larger spread of conditions to be examined, which is beneficial when the required complexity of model is not known for accurate predictions to be made (Box et al., 2005). The single, interactive and quadratic effects of the independent variables (Binder (A), Solvent (B), Pigment (C) and Additives (D) were evaluated to optimize the Viscosity of the formulation $(\mathrm{Y})$.

The $2^{4}$ CCD experimental matrix (Table 2) was developed by Design Expert Version 10, State Ease U.S.A with 30 runs (16 factorial points, 8 centre points and 6 axial points). The experiments were performed in random order to avoid systematic error. Table 1 displays experimental boundary of the independent variables for the optimal solution evaluation. A mathematical relationship between the dependent variable: viscosity $(\mathrm{Y})$ and the independent variables: Binder (A), Solvent (B), Pigment (C) and Additives (D) may be described as:

$$
Y=f(A, B, C, D)
$$

Table 1: Experimental range of the independent variables

\begin{tabular}{ccccccc}
\hline Independent variable & Symbol & \multicolumn{5}{c}{ Range and Levels } \\
\cline { 3 - 7 } & & $-\alpha$ & -1 & 0 & +1 & $+\alpha$ \\
\hline Binder (g) & $\mathrm{A}$ & 10 & 70 & 130 & 190 & 250 \\
Solvent (g) & $\mathrm{B}$ & 5 & 30 & 55 & 80 & 105 \\
Pigment (g) & $\mathrm{C}$ & 5 & 15 & 25 & 35 & 45 \\
Additives (g) & $\mathrm{D}$ & 0 & 1 & 2 & 3 & 4 \\
\hline
\end{tabular}


The relationship of the resultant response and the independent variables was approximated by the secondorder polynomial (equation 4).

$$
Y=\beta_{0}+\sum_{i=1}^{K} \beta_{i} x_{i}+\sum_{i=1}^{K} \beta_{i i} x_{i}^{2}+\sum_{i=1}^{K-1} \sum_{j=i+1}^{K} \beta_{i j} x_{i} x_{j}
$$

Where $\mathrm{Y}$ is the predicted viscosity, $\beta_{0}$ is a constant, $\beta_{\mathrm{i}}, \beta_{\mathrm{ij}}$, $\beta_{\text {ii }}$ are linear, interaction and squared coefficients respectively, $x_{i}$ and $x_{j}$ are independent variables, $K$ is the number of factors. Analysis of Variance (ANOVA) was used to determine the statistical significance of each regression coefficient on the response (Y). According to Uzoh and Onukwuli (2014), the determination of unknown coefficient of equation (4) entails judicious transformation of the actual values of the four control variables at various levels over which the experiments were executed to their coded equivalents using -1 and +1 notations to designate low and high level factor setting and ' $\pm \alpha$ ' and ' 0 ' for axial and centre points, respectively. It has been shown that working with the coded variables enhances matrix transformation and helps in results analyses. Equation (4) was fitted to the experimental data to obtain the final predictive equation for the formulation in terms of the coded variables.

\section{Artificial neural network}

A three-layered feed-forward architecture of artificial neural network (Multilayer perceptron [MLP]) trained by the back-propagation algorithm was proposed to build a predictive model with the first layer of four neurons representing the independent variables (input layer), the second and third layers of neurons represent the hidden layer and output layer (viscosity) respectively (Okoye et al., 2019). Each of the neurons in the first layer is connected to one or more layers of the hidden neurons that represent nonlinear activation functions. These neurons are in turn connected to a final level of output neurons and, through the use of learning algorithms, the relative influence of each input neuron and their complex interactions on the observed result can be discerned(Pilkington et al., 2014).

Neurons are needed in the hidden layer in order to minimize the deviation of ANN predictions from experimental results. These neurons are connected by weights that are modified during the learning algorithms. Matlab 2015 (MathWorks) was used in developing the MLP. Fig 1 depicts the architecture of the developed ANN for the modeling of viscometry behavior of the paint formulations.

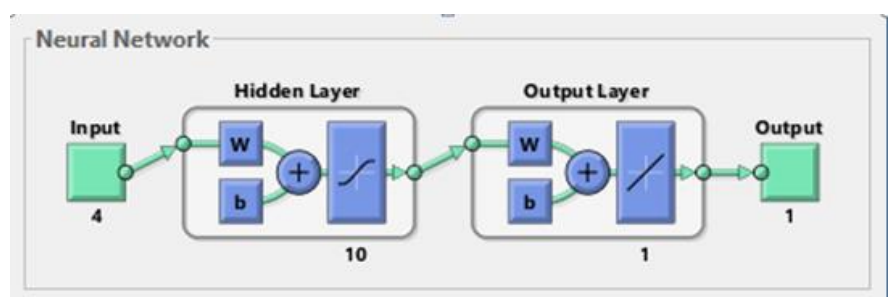

Fig 1: ANN architecture

\section{Comparison of RSM and ANN models}

The capability of the RSM and ANN models in capturing the experimental data was evaluated using the absolute average deviation (AAD\%) error function (equation 5) and the coefficient of determination $\left(\mathrm{R}^{2}\right)$.

$$
\operatorname{AAD}(\%)=\left(\frac{1}{n} \sum_{i=1}^{n}\left\{\frac{y_{i, p r e d}-y_{i, e x p}}{y_{i, \theta x p}}\right\}\right) \times 100
$$

where $n, y_{i, p r e d}$, and $y_{i, e x p}$ represent the number of points, predicted and experimental values respectively. The lower the $\operatorname{AAD}(\%)$ value and the higher the value of $\mathrm{R}^{2}$, the better will be the goodness of fit. The range of $\mathrm{R}^{2}$ is from 0 to $1 . \mathrm{R}^{2}$ values closer to 1 indicate the model's superiority in predicting the behavior of the system (Yolmeh et al., 2014).

\section{RESULTS AND DISCUSSION}

\section{Grafting}

The grafting efficiency (GE \%) of $75.3 \%$ and grafting yield $(\mathrm{G} \%)$ of $76.25 \%$ were calculated from equations 1 and 2 . These values calculated for GE\% and G\% suggest effective graft copolymerization of methyl methacrylate on to the maleilated chitosan.

\section{FTIR}

FTIR analysis was conducted to detect the presence of unknown substances present in the samples. The analysis revealed the vibrational origin of the amine, carbonyl and alcoholic groups of chitosan and the corresponding graft copolymers. Figure 2 represent the FTIR spectrum of the chitosan generated from periwinkle shell. Peaks 3424.36 $\mathrm{cm}^{-1}, 2933.83 \mathrm{~cm}^{-1}$ revealed the presence of N-H stretching and C-H stretch (IRChart, 2021) respectively. 1848.48 $\mathrm{cm}^{-1}, 1617.93 \mathrm{~cm}^{-1}$ and $1390.76 \mathrm{~cm}^{-1}$ were assigned to $\mathrm{C}-\mathrm{H}$ bending, primary amine(Merc, 2021), NH bend (Coates, 2000) and O-H bending (Merc, 2021) respectively. 


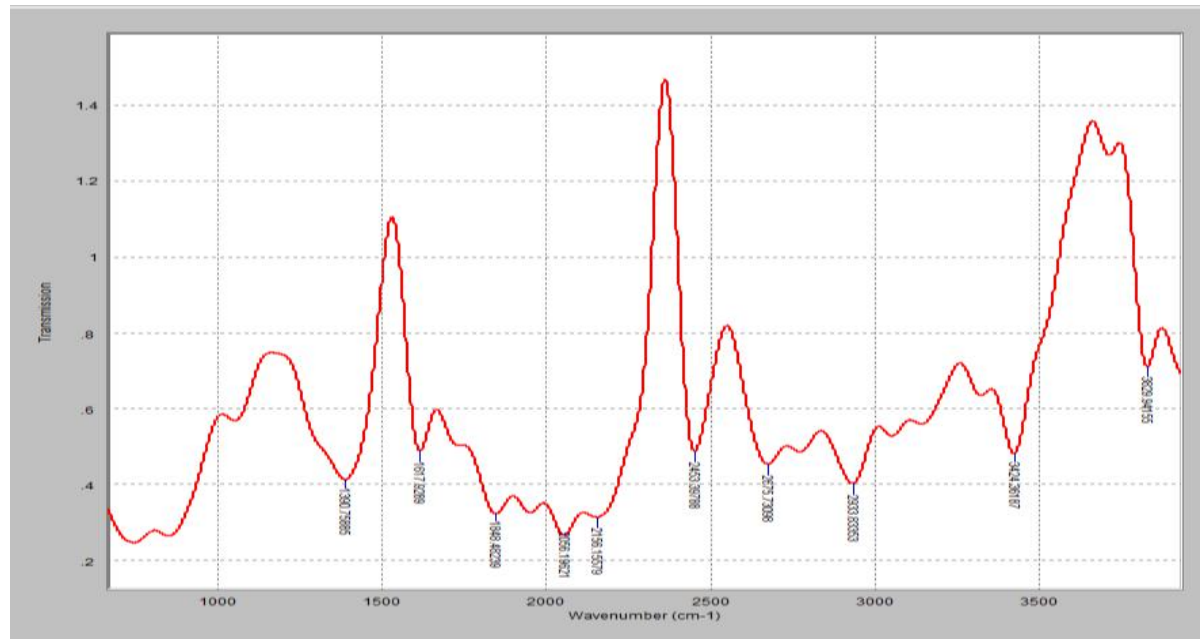

Fig. 2: FTIR Spectrum of Chitosan

Figure 3 is a graph of $\%$ Transmittance vs wave number for chitosan-g-maleic anhydride. The spectrum reveals a conspicuous peak at $1619.01 \mathrm{~cm}^{-1}$ establishing the presence of $\mathrm{C}=\mathrm{C}$ bond (Merc, 2021). This confirmed the grafting of maleic anhydride group on to chitosan (Hemalatha and Sudha, 2011).

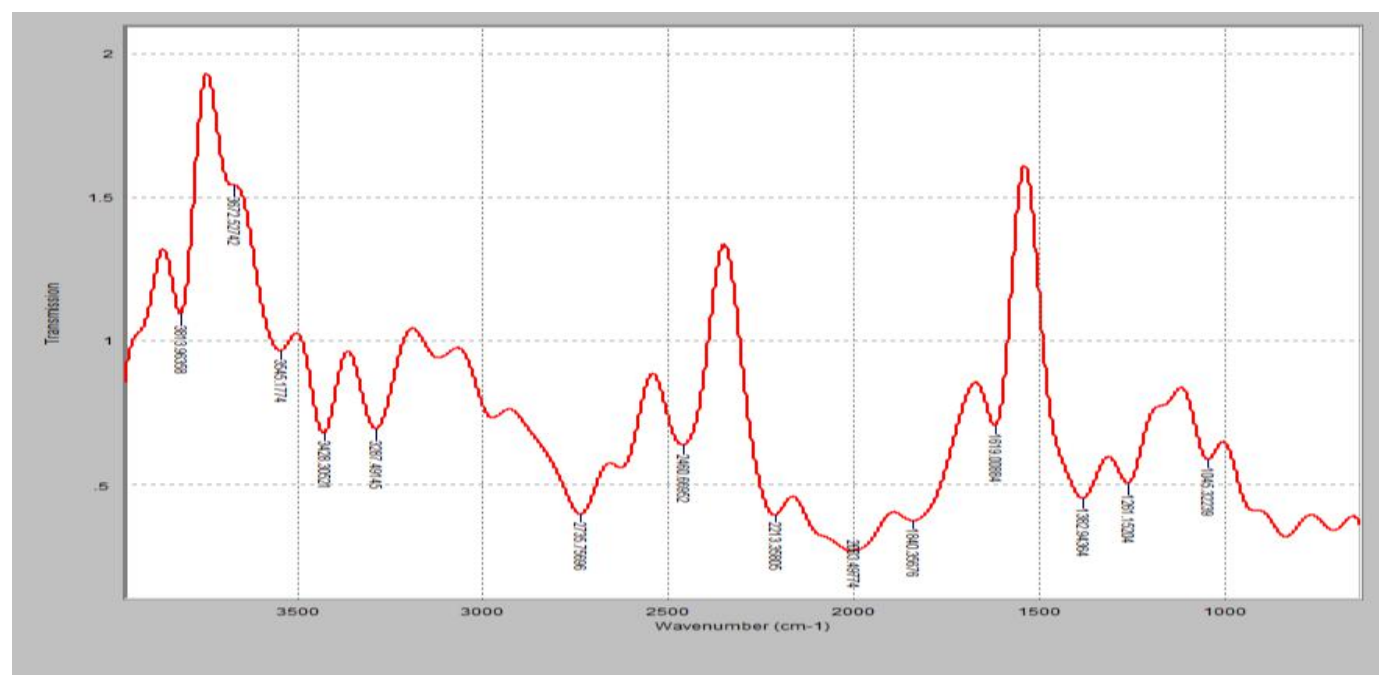

Fig. 3: FTIR Spectrum of Chitosan-g-maleic anhydride

Chitosan-g-maleic anhydride-g-(Methyl methacrylate) copolymer is a product of further grafting of maleilated chitosan with methyl methacrylate. From the FTIR spectrum (Figure 4) depicted additional sharp peaks at $1388.62 \mathrm{~cm}^{-1}, 1625.44 \mathrm{~cm}^{-1}$ and $2805.33 \mathrm{~cm}^{-1}$ showing the presence of carbonyl compounds. Methyl C-H asym./sym. stretch of the methacrylate structure forms part of
Chitosan-g-maleic anhydride-g-(Methyl methacrylate) copolymer are in infrared (IR) range of (2880-2860) $\mathrm{cm}^{-1}$ having peak positions close to $2854 \mathrm{~cm}^{-1}$ as depicted in Figure 4 (Coates, 2000). This substantially confirmed the grafting of methyl methacrylate to maleilated chitosan (Hemalatha and Sudha, 2011). 


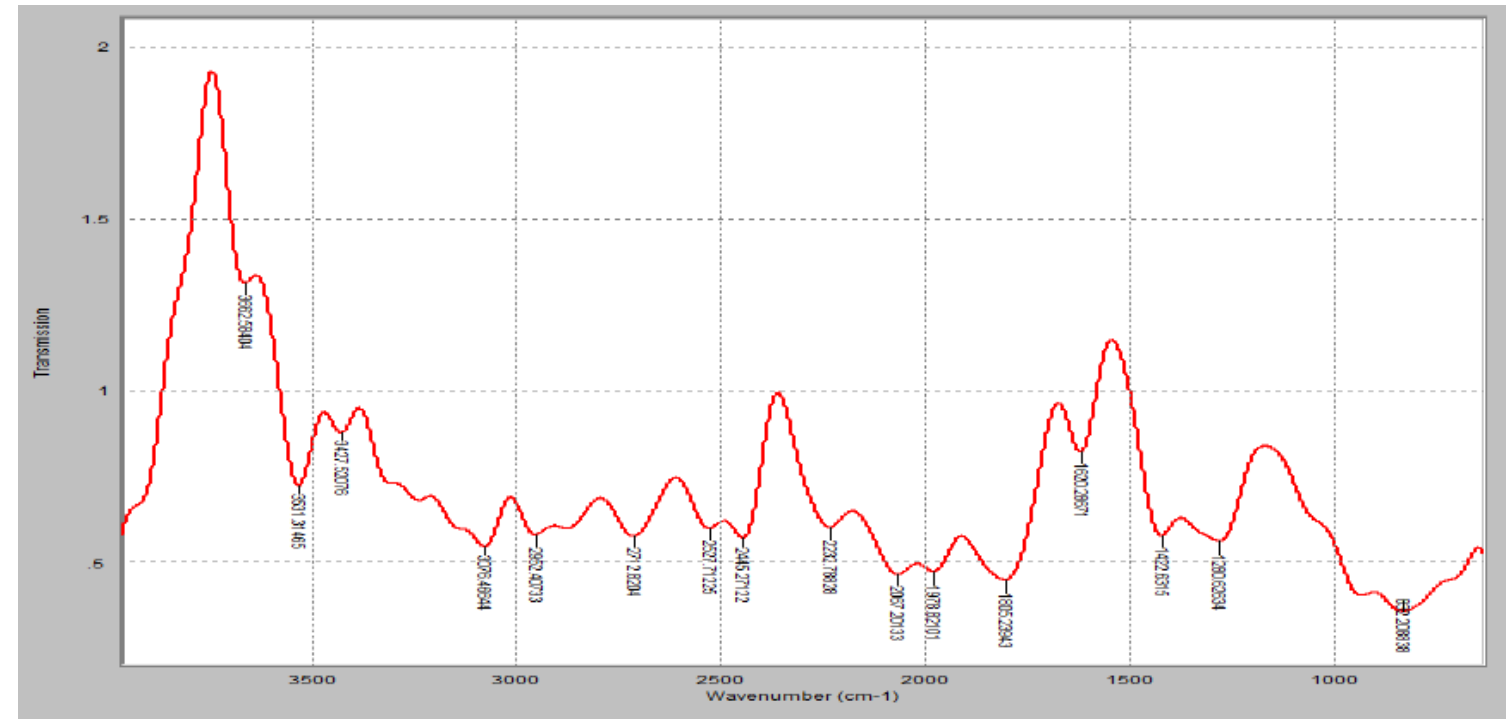

Fig. 4: FTIR Spectrum of Chitosan-g-maleic anhydride-g-(Methyl methacrylate)

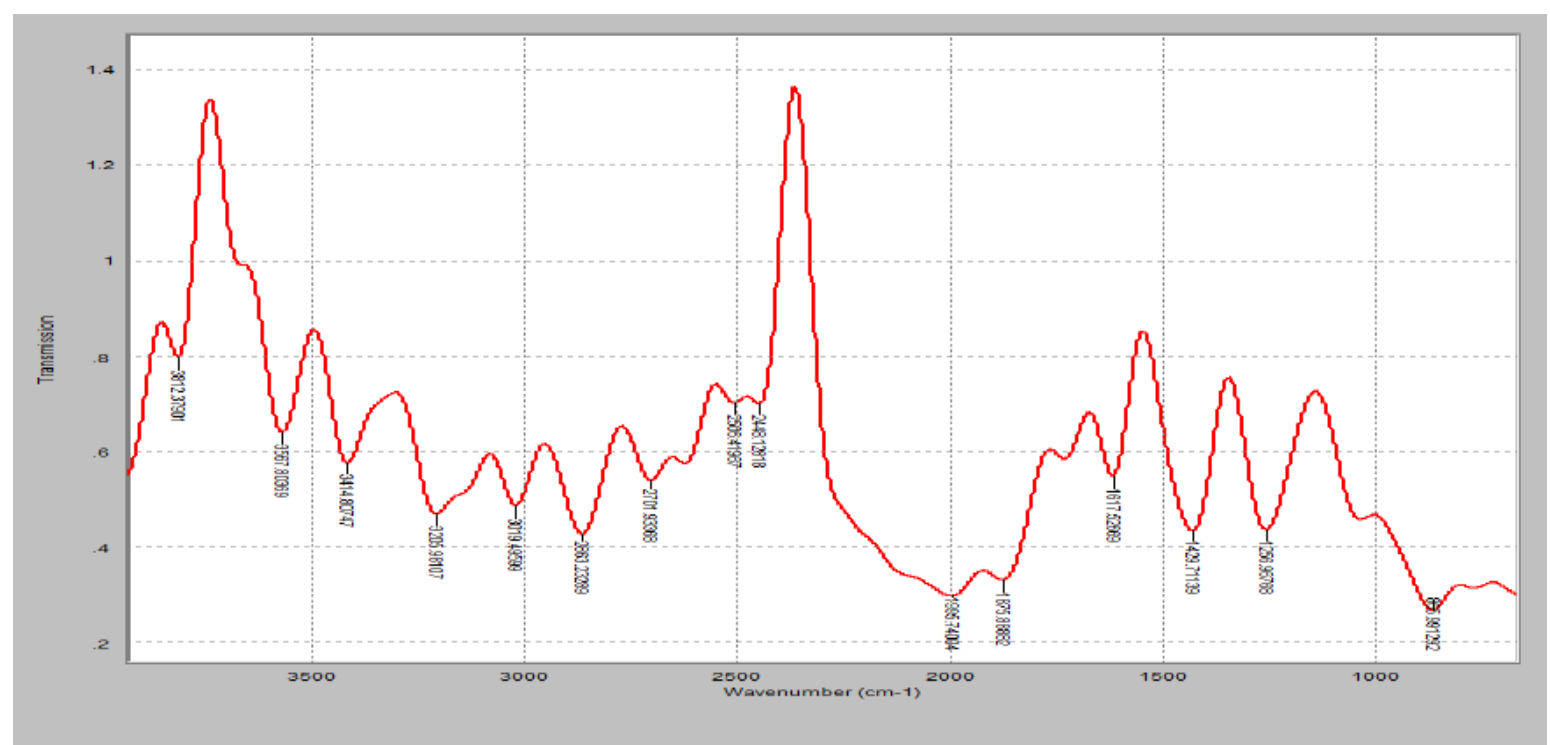

Fig. 5: FTIR Spectrum of formulated car paint

Figures 5 and 6 show the graph of FTIR spectra for the formulated car paint and modified car paint. The FTIR spectrum for the car paint identified peaks $1256.97 \mathrm{~cm}^{-1}$, $1617.53 \mathrm{~cm}^{-1}, 1995.74 \mathrm{~cm}^{-1}$ and $2863.23 \mathrm{~cm}^{-1}$ representing C-O stretch, $\mathrm{C}=\mathrm{O}$ bonds (www.orgchemboulder.com), C$\mathrm{H}$ bending (Coates, 2000), aromatic compound (Merck, 2021) and methylene C-H asym./sym. Stretch (Coates, 2000) as represented within the alkyd resin paint structure. Figure 6, had additional peaks at $1060.46 \mathrm{~cm}^{-1}, 1344.09$ $\mathrm{cm}^{-1}, 2718.03 \mathrm{~cm}^{-1}, 2827.56 \mathrm{~cm}^{-1}, 3386.70 \mathrm{~cm}^{-1}$ and
$3446.89 \mathrm{~cm}^{-1}$ showing the presence of primary amine $\mathrm{CN}$ stretch, aromatic secondary amine $\mathrm{CN}$ stretch (Coates, 2000), O-H stretching (Merc, 2021), methyl ether $\mathrm{O}-\mathrm{CH}_{3}$, aliphatic primary amine NH stretch and hydroxyl group, $\mathrm{H}$-bonded $\mathrm{OH}$ stretch. These show the presence of Chitosan-g-maleic anhydride-g-(Methyl methacrylate) copolymer used in the formulated self healing paint. The observed shifts in peaks of the functional groups may be as a result of interactions with other additives used in the paint formulation. 


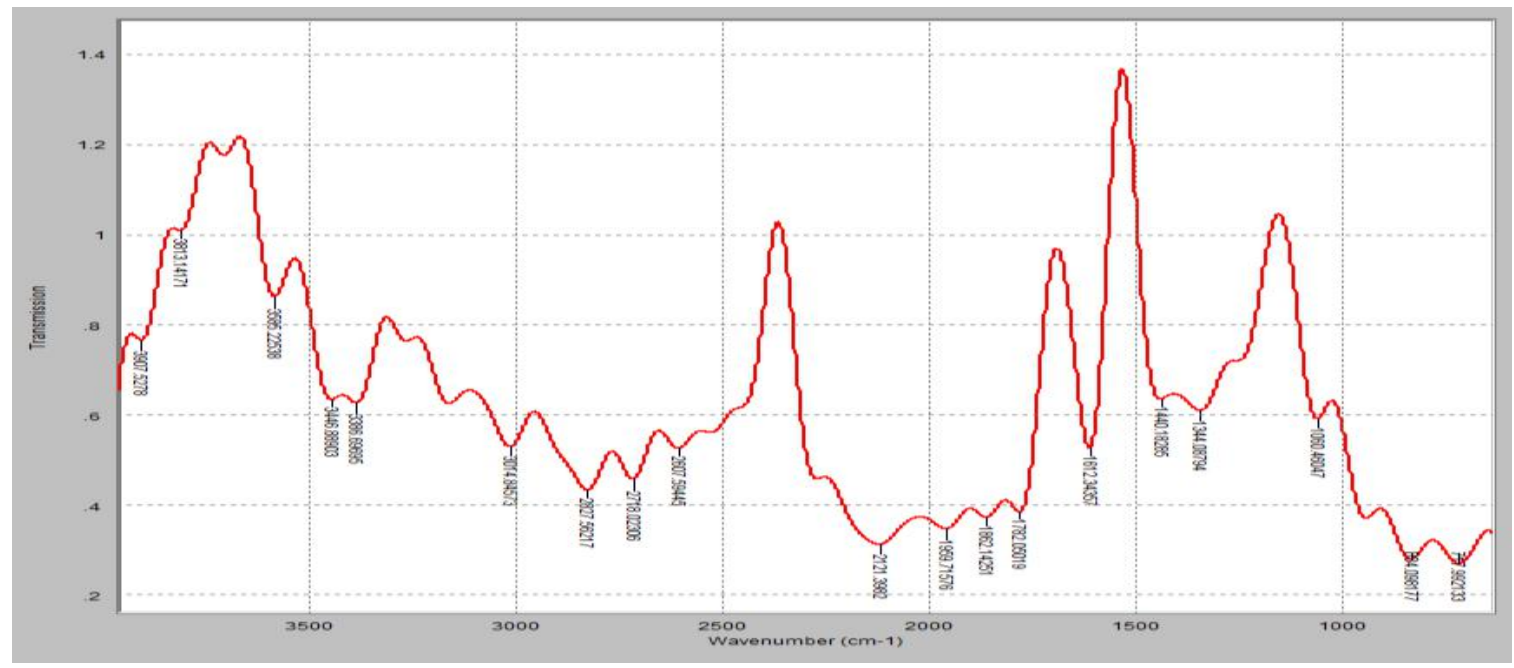

Fig. 6: FTIR Spectrum of the formulated self healing paint

\section{Physic-chemical characterization}

The drying time, adhesion and chemical resistance properties were measured. At the end of the drying time test period according to the method reported, the filter paper fell of the test film with a light tap. The resistance of the paint formulations was tested in a mixture of acetone, demineralized water and isopropyl alcohol medium after 24 hours. The morphology of the substrates did not change (no stains were recorded) after the medium's drops on them. This outcome shows that the paint formulations have high chemical resistance. The formulations sprayed on metal surface portrayed strong adherence characteristics as no flaking or ribboning was observed after making the cuts and applying the adhesive tape. It is reported that hydroxyl groups in the structure of the resin improved the adhesion to the substrates. The outcome of these characterization results fall within standard acceptable limit, therefore suggest that the product is a good paint.

\section{Response surface methodology Model}

A set of 30-experimental runs generated by a $2^{4}$ central composite design were performed to examine the combined effect of the controllable input variables (binder, solvent, pigment and additives) on the response (viscosity). Experimental data was compared with RSM model's predictions (Table 2). The experimental data was fitted into linear, 2FI, quadratic and cubic models to test the adequacy of the models in describing the system.

As recorded in Table 3, the quadratic model presents the lowest prediction error sum of squares (PRESS) value of 1033950 compared to cubic (7816944), 2FI (6025394) and linear (8831846) models. Also, the quadratic model's predicted R-squared value (0.9494) can best be approximated to 1 when compared to $0.5678,0.7051$ and 0.6175 for linear, 2FI and cubic models. Model with the lowest PRESS value suggests highest predictability. From these findings, the quadratic model best correlates the predicted and the experimental response data for the investigated paint formulations, therefore, was selected for further computations on the experimental data. Quadratic model's predicted and adjusted R-squared values of 0.9494 and 0.9830 are considered to be in reasonable agreement having a difference less than 0.2. According to Jie (2014), the predicted R-square considers all effects and adjusted Rsquare considers only square effects and interaction effects between two input variables. The quadratic model's coefficient of determination, $\mathrm{R}^{2}$, value of 0.9912 suggests that $99.12 \%$ of the total variation could be explained by the model.

ANOVA results for Response Surface Quadratic model is presented in Table 4. The F-value of 120.89 and the very low value $(<0.0001)$ recorded for the model P-value confirms the significance of the model. Statistical significance of the model's terms can be measured using the P-value. It is seen on Table 4 that model terms C, D, $\mathrm{AC}, \mathrm{AD}, \mathrm{BC}, \mathrm{BD}, \mathrm{CD}, \mathrm{C}^{2}$ and $\mathrm{D}^{2}$ are statistically insignificant $(\mathrm{P}>0.05)$. According to Pilkington (2014), higher Fisher's F-test values and lower $\mathrm{P}$ values indicate the relative significance of each model term.

The resultant quadratic model equation generated after regression analyses is given by:

In coded values:

$\mathrm{Y}=2208+567.42 \mathrm{~A}-527.58 \mathrm{~B}+40.08 \mathrm{C}-33.08 \mathrm{D}+$

$409.88 \mathrm{AB}+23.25 \mathrm{AC}-38.25 \mathrm{AD}+28.63 \mathrm{BC}-36.37 \mathrm{BD}$

$+35.50 \mathrm{CD}-273.23 \mathrm{~A}^{2}-211.35 \mathrm{~B}^{2}-11.48 \mathrm{C}^{2}-9.48 \mathrm{D}^{2}$

(6)

In actual values, equation 7 is written as:

$\mathrm{Y}=1778.78+14.47$ Binder -19.38 Solvent -8.69Pigment +78.98Additives +0.27 Binder*Solvent 
+0.04Binder*Pigment -0.64Binder*Additives

+0.11 Solvent*Pigments -1.45 Solvent*Additives

+3.55 Pigment*Additives -0.08 Binder $^{2}-0.34$ Solvent $^{2}-$

0.11 Pigment $^{2}-9.48$ Additives $^{2}$.

The unitless coefficients of the second order polynomial model design equations 6 and 7 were determined by multiple regression analysis. Positive sign in front of the terms indicates synergistic effect while negative sign indicates antagonistic effect of the factor. Statistically, the key contributory variables in viscosity variation are the binder ( $\mathrm{p}$-value $<0.0001$ ) and solvent ( $\mathrm{p}$-value $<0.0001$ ). By sign convention, increase in binder mass in the formulation is synergetic to the response (viscosity) while increase in solvent mass in the formulation is antagonistic to viscosity.

Table 2: Design Matrix for the paint formulation

\begin{tabular}{|c|c|c|c|c|c|c|c|}
\hline \multirow[t]{2}{*}{ No. } & \multicolumn{4}{|c|}{ Independent factors } & \multicolumn{3}{|c|}{ Viscosity (mPa.s) } \\
\hline & Binder (g) & $\begin{array}{l}\text { Solvent } \\
(\mathrm{g})\end{array}$ & Pigment (g) & Additives (g) & Experimental & $\begin{array}{l}\text { RSM } \\
\text { Predicted }\end{array}$ & $\begin{array}{l}\text { ANN } \\
\text { predicted }\end{array}$ \\
\hline 1 & 70 & 80 & 15 & 3 & 143 & 85.42 & 132 \\
\hline 2 & 190 & 80 & 15 & 3 & 1654 & 1917 & 1646.9 \\
\hline 3 & 70 & 80 & 15 & 1 & 155 & 218.83 & 115.4 \\
\hline 4 & 190 & 30 & 15 & 3 & 2359 & 2282.42 & 2308.2 \\
\hline 5 & 10 & 55 & 25 & 2 & 20 & -19.75 & 20.3 \\
\hline 6 & 70 & 80 & 35 & 3 & 167 & 247.33 & 186.7 \\
\hline 7 & 130 & 55 & 25 & 2 & 2208 & 2208 & 2208.3 \\
\hline 8 & 70 & 30 & 35 & 3 & 2105 & 2137.75 & 2327.4 \\
\hline 9 & 130 & 55 & 25 & 2 & 2208 & 2208 & 2208.3 \\
\hline 10 & 190 & 30 & 15 & 1 & 2374 & 2423.33 & 2269.9 \\
\hline 11 & 70 & 80 & 35 & 1 & 196 & 238.75 & 95.8 \\
\hline 12 & 130 & 55 & 45 & 2 & 2225 & 2242.25 & 2243.7 \\
\hline 13 & 190 & 80 & 15 & 1 & 2270 & 2203.42 & 2259.3 \\
\hline 14 & 70 & 30 & 35 & 1 & 2117 & 1983.67 & 2018.1 \\
\hline 15 & 130 & 55 & 25 & 0 & 2232 & 2236.25 & 2252 \\
\hline 16 & 70 & 30 & 15 & 1 & 2016 & 2078.25 & 1987.7 \\
\hline 17 & 130 & 55 & 25 & 2 & 2208 & 2208 & 2208.3 \\
\hline 18 & 250 & 55 & 25 & 2 & 2306 & 2249.92 & 2273 \\
\hline 19 & 130 & 105 & 25 & 2 & 397 & 307.42 & 368.4 \\
\hline 20 & 190 & 80 & 35 & 1 & 2271 & 2316.33 & 2351.8 \\
\hline 21 & 130 & 5 & 25 & 2 & 2424 & 2417.75 & 2434.2 \\
\hline 22 & 70 & 30 & 15 & 3 & 2006 & 2090.33 & 2271.2 \\
\hline 23 & 130 & 55 & 25 & 2 & 2208 & 2208 & 2208.3 \\
\hline 24 & 190 & 30 & 35 & 1 & 2398 & 2421.75 & 2459.6 \\
\hline 25 & 130 & 55 & 25 & 4 & 2204 & 2103.92 & 2210.2 \\
\hline 26 & 130 & 55 & 5 & 2 & 2195 & 2081.92 & 2132.6 \\
\hline 27 & 190 & 30 & 35 & 3 & 2357 & 2422.83 & 2343.6 \\
\hline 28 & 130 & 55 & 25 & 2 & 2208 & 2208 & 2208.3 \\
\hline 29 & 130 & 55 & 25 & 2 & 2208 & 2208 & 2208.3 \\
\hline 30 & 190 & 80 & 35 & 3 & 2268 & 2171.92 & 2280.5 \\
\hline
\end{tabular}


Table 3: Model Summary Statistics

\begin{tabular}{|c|c|c|c|c|c|c|}
\hline & Std. & & Adjusted & Predicted & & \\
\hline Source & Dev. & R-Squared & R-Squared & R-Squared & PRESS & \\
\hline Linear & 488.33 & 0.7082 & 0.6616 & 0.5678 & 8831846 & \\
\hline $2 \mathrm{FI}$ & 409.57 & 0.8440 & 0.7619 & 0.7051 & 6025394 & \\
\hline Quadratic & 109.39 & 0.9912 & 0.9830 & 0.9494 & 1033950 & Suggested \\
\hline Cubic & 88.06 & 0.9973 & 0.9890 & 0.6175 & 7816944 & Aliased \\
\hline
\end{tabular}

Table 4: ANOVA for Response Surface Quadratic model for paint formulation

\begin{tabular}{|c|c|c|c|c|c|c|}
\hline \multicolumn{7}{|c|}{ Analysis of variance table [Partial sum of squares - Type III] } \\
\hline & Sum of & & Mean & $\mathrm{F}$ & $\mathrm{p}$-value & \\
\hline Source & Squares & $\mathrm{df}$ & Square & Value & Prob $>$ F & \\
\hline Model & 20254284 & 14 & 1446735 & 120.8936 & $<0.0001$ & Significant \\
\hline A-Binder & 7727080 & 1 & 7727080 & 645.6984 & $<0.0001$ & \\
\hline B-Solvent & 6680260 & 1 & 6680260 & 558.2229 & $<0.0001$ & \\
\hline $\begin{array}{c}\text { C- } \\
\text { Pigment }\end{array}$ & 38560.17 & 1 & 38560.17 & 3.222205 & 0.0928 & \\
\hline $\begin{array}{c}\text { D- } \\
\text { Additives }\end{array}$ & 26268.17 & 1 & 26268.17 & 2.195048 & 0.1592 & \\
\hline $\mathrm{AB}$ & 2687960 & 1 & 2687960 & 224.6142 & $<0.0001$ & \\
\hline $\mathrm{AC}$ & 8649 & 1 & 8649 & 0.722737 & 0.4086 & \\
\hline $\mathrm{AD}$ & 23409 & 1 & 23409 & 1.956128 & 0.1823 & \\
\hline $\mathrm{BC}$ & 13110.25 & 1 & 13110.25 & 1.095533 & 0.3118 & \\
\hline $\mathrm{BD}$ & 21170.25 & 1 & 21170.25 & 1.769051 & 0.2034 & \\
\hline $\mathrm{CD}$ & 20164 & 1 & 20164 & 1.684965 & 0.2139 & \\
\hline $\mathrm{A}^{\wedge} 2$ & 2047657 & 1 & 2047657 & 171.1085 & $<0.0001$ & \\
\hline $\mathrm{B}^{\wedge} 2$ & 1225250 & 1 & 1225250 & 102.3857 & $<0.0001$ & \\
\hline $\mathrm{C}^{\wedge} 2$ & 3614.298 & 1 & 3614.298 & 0.302022 & 0.5907 & \\
\hline $\mathrm{D}^{\wedge} 2$ & 2464.583 & 1 & 2464.583 & 0.205948 & 0.6565 & \\
\hline Residual & 179505.2 & 15 & 11967.01 & & & \\
\hline $\begin{array}{c}\text { Lack of } \\
\text { Fit }\end{array}$ & 179505.2 & 10 & 17950.52 & & & \\
\hline Pure Error & 0 & 5 & 0 & & & \\
\hline Cor Total & 20433789 & 29 & & & & \\
\hline
\end{tabular}


The normality of residuals was investigated from the trend observed in Figure 7. The plots show the presence of influential values (outliers). The plotted points follow a straight line with very few outliers. The trend followed is an indication that the residuals are normally distributed.

Figure 8 reveals the extent of the model's predictability within the design space. It is expected that the plots should scatter around the $45^{\circ}$ line. For robust correlation to be established between the actual and the predicted values. It can be seen from the predicted versus actual plot that the actual response values closely matched the predicted line.

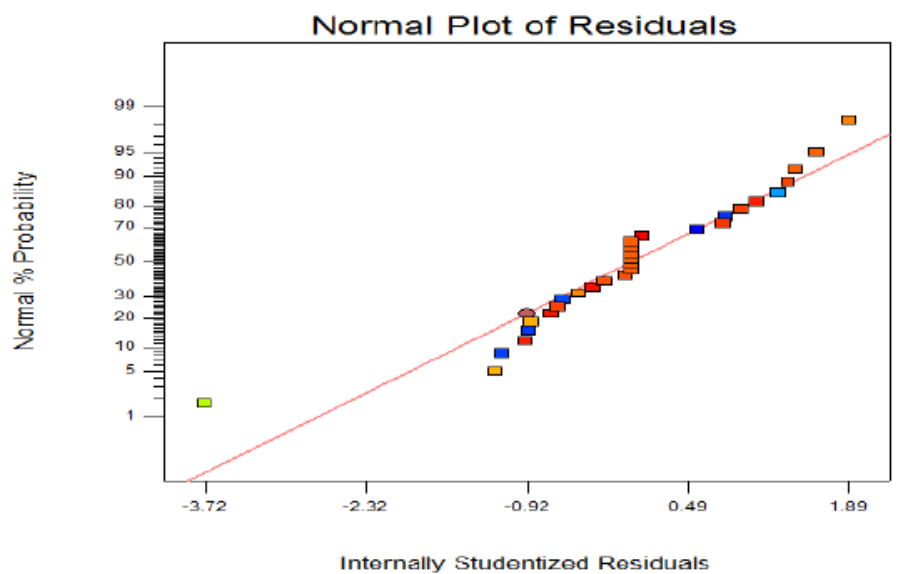

Fig 7: Normal probability plot of residuals for viscosity response on paint formulation

Fig 8: RSM predicted vs Actual plot for viscosity response on paint formulation

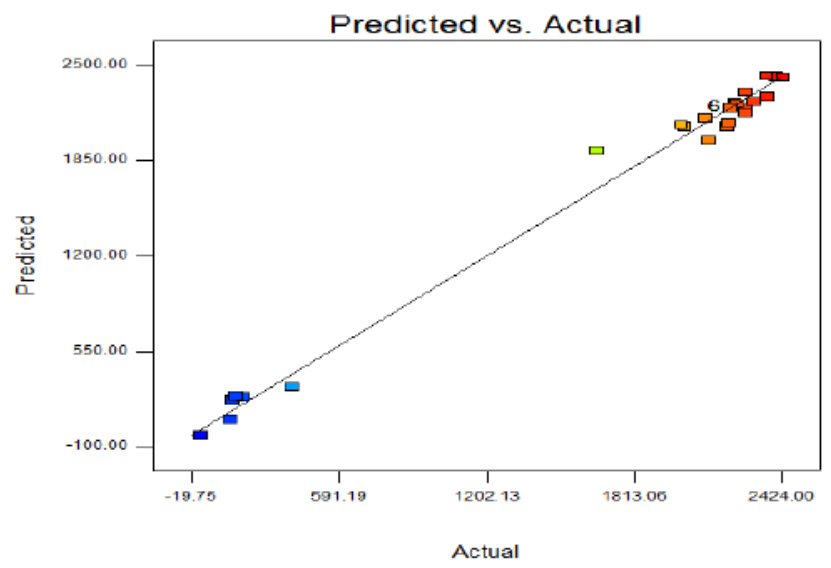

Fig 8: RSM predicted vs Actual plot for viscosity response on paint formulation

Figure 9 reveals the combined interactive effect of the binder and solvent on viscosity variation of the paint formulations with other variables held at their mid-points (pigment=25g; additives $=2 \mathrm{~g}$ ). As the mass of the binder was reviewed upwards, the synergetic effect on the response was clearly observed. Upward review of the mass of solvent introduced in the formulation displayed continuous negative effect on the response. The curved architecture displayed on the canopy is an indication that the model contains statistically significant model terms.

Examining the effect of binder and pigment on viscosity (Figure 10) having other variables kept at their midpoints ( solvent $=55 \mathrm{~g}$; additives $=2 \mathrm{~g}$ ) also shows the positive effect of the binder on the response as it is reviewed upwards. The increase in the mass of pigment from $16-$ $35 \mathrm{~g}$ on the canopy did not significantly affect the value of the response variable. This is in line with the findings from the ANOVA table (Table 4).

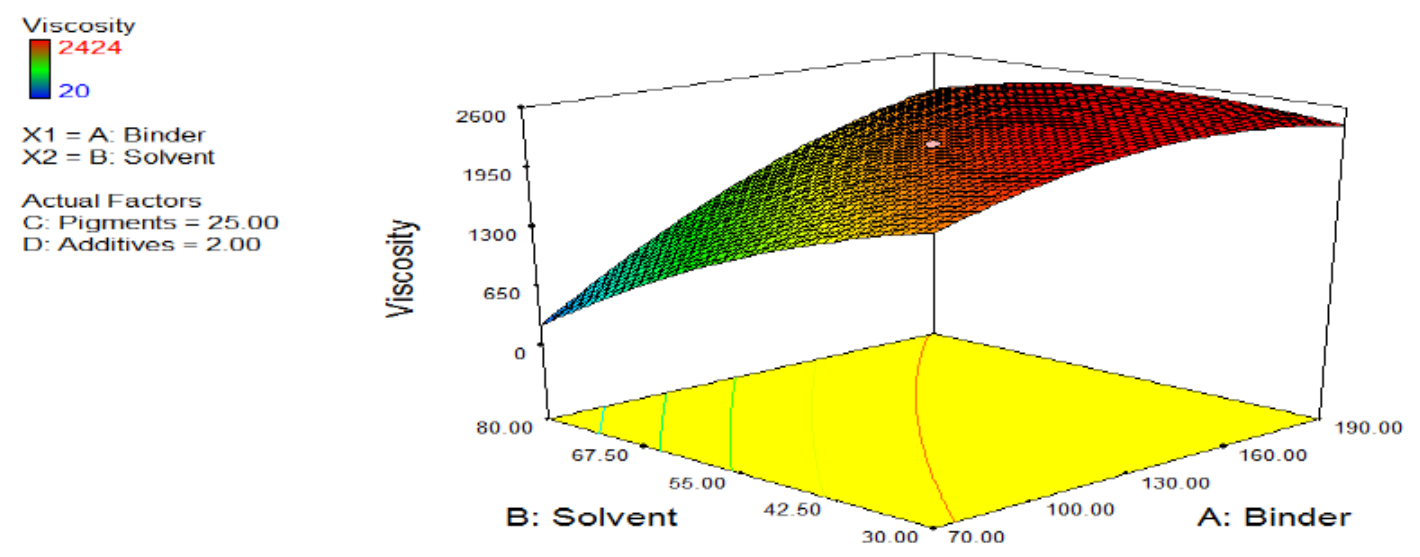

Fig 9: 3D Surface plot for combined effect of binder and solvent on viscosity 

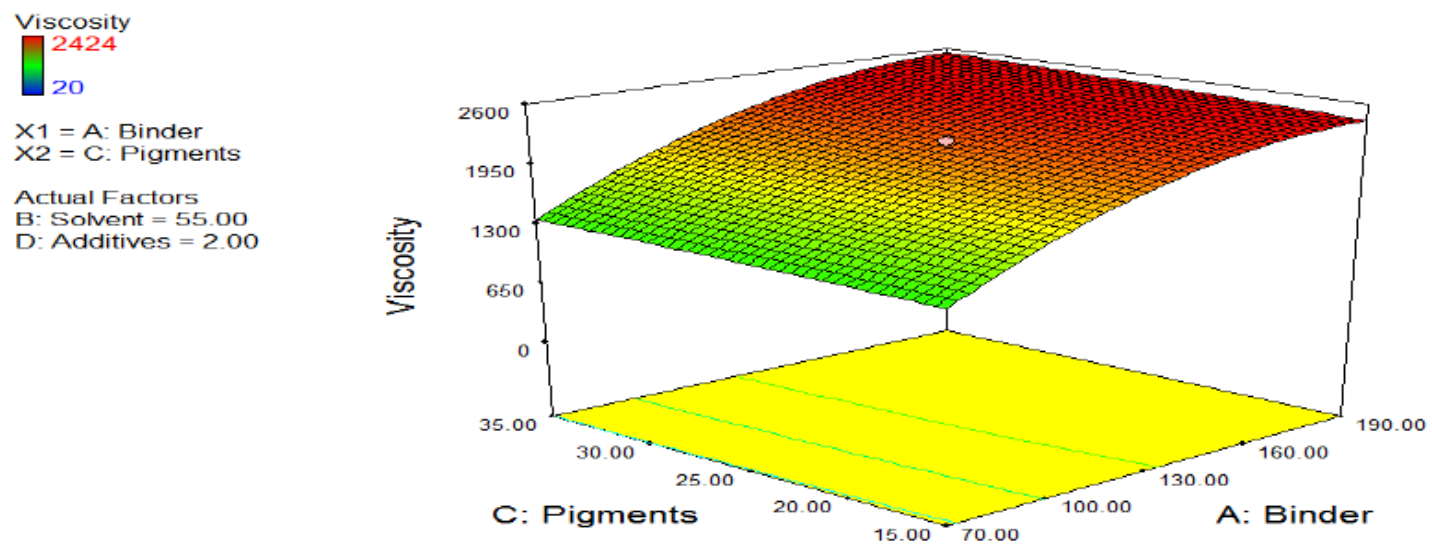

Fig 10: 3D Surface plot for combined effect of pigment and binder on viscosity

\section{Artificial Neural Network}

The data in the design matrix (Table 2) was used in training the neural network. The feed-forward ANN architecture was used in building the ANN model. Fig 11 reveals that the MLP network has three layers: input, hidden and output layer. The input layer consists of four neurons representing the process independent variables (binder, solvent, pigment and additives). The whole investigated data was partitioned into three: training, validation and testing. This was done to avoid overtraining and over-paramaterization (Desai et al., 2008). $70 \%$ of the data set (21 experimental runs) were used to train the network while the remaining results $(30 \%)$ were split evenly between validation and testing. ANN's extent of prediction of the experimental data adjudged by the coefficient of determination $\left(\mathrm{R}^{2}\right)$ values was shown in Figure 11. The ANN model predicted data is presented on Table 2.
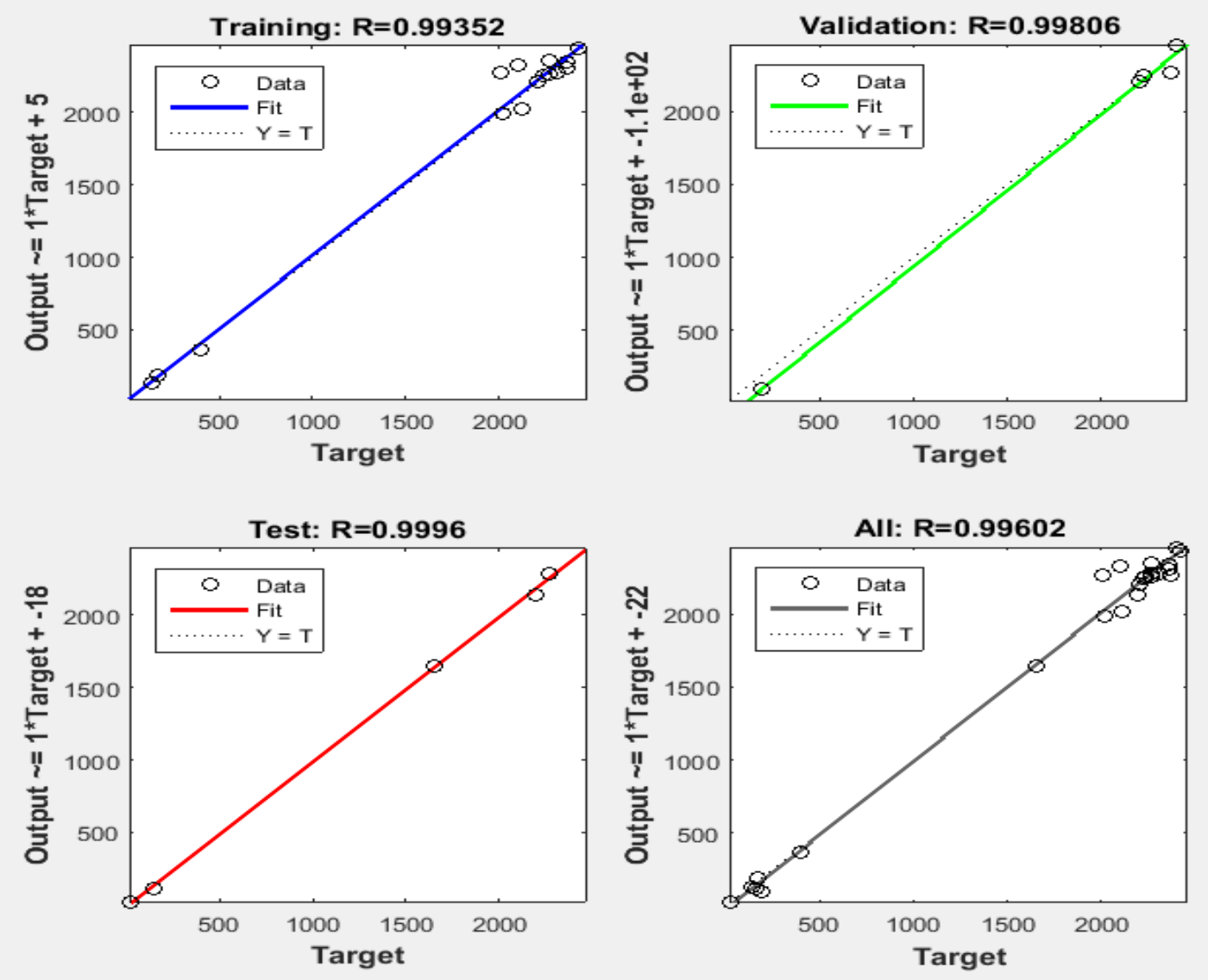

Fig 11: ANN model regression plots for training, validation, test and all prediction data 


\section{Comparison of RSM and ANN Models}

The closeness of the RSM and ANN models' predictions to the experimental data was measured by fitting experimental and predicted values in equation 5. From the $\operatorname{AAD}(\%)$ estimation, ANN and RSM gave $4.12 \%$ and $5.77 \%$ respectively. From Figure 12, 0.992 and 0.991 coefficient of determination values were presented for ANN and RSM respectively. The result indicates that both the ANN and RSM predicted the experimental values to a great extent, however, the ANN model marginally outperformed the RSM model.

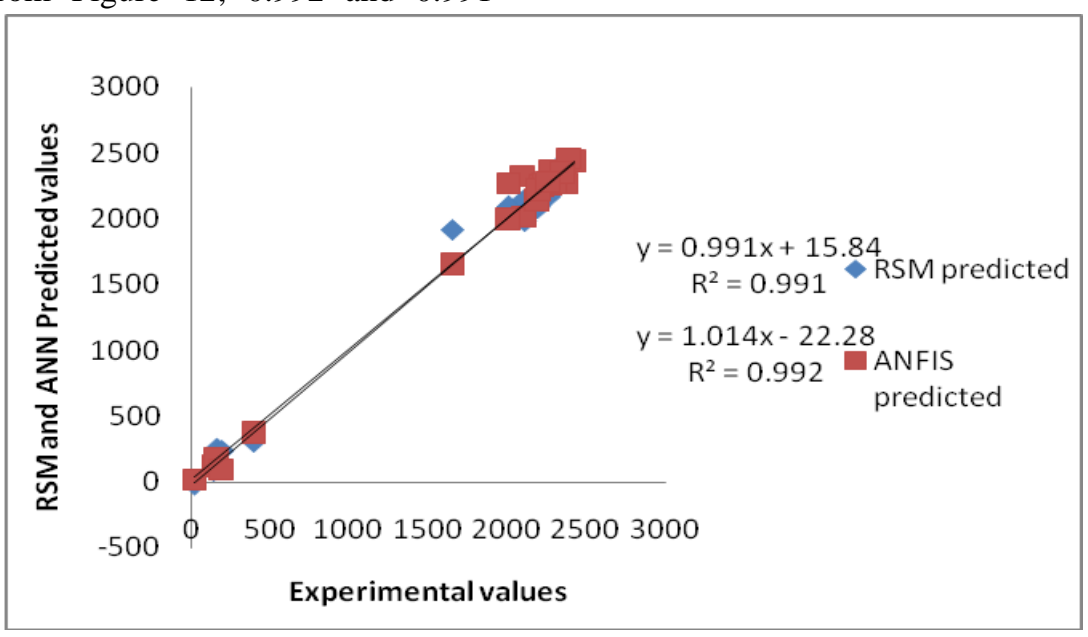

Fig.12: Plot for ANN and RSM models' comparison

\section{Process optimization}

The viscosity of paint is one of the vital quality control test that is necessary for product delivery and spray specifications. The data presented on Table 2 presents paint for high and low viscous formulations which can serve depending on the functionality. According to Schoff (2021), there is a rule of the thumb in the paint industry that a viscosity of approximately $100 \mathrm{cps}$ provides acceptable spraying, brushing or roll coating. In line with this objective, a systematic combination of the input variables in equation 6 aided by Design Expert Software version 10 was employed to generate optimal solutions. Table 5 shows CCD optimum predicted conditions and validation experimental result. It is seen that viscosity of the paint experimental formulation $(102 \mathrm{mPa} . \mathrm{s})$ obtained at optimal controllable variable condition closely matches with the CCD predicted optimal response (99.85mPa.s).

Table 5: CCD optimum predicted/validation result

\begin{tabular}{lllll}
\hline Binder & Solvent & Pigment & Additives & \multicolumn{2}{c}{ Viscosity } \\
\cline { 3 - 5 } & & & $\begin{array}{l}\text { CCD Optimal } \\
\text { Response }\end{array}$ & $\begin{array}{c}\text { Experimental } \\
\text { Validation }\end{array}$ \\
\hline 70.24 & 79.99 & 15.72 & 3 & 99.85 \\
\hline
\end{tabular}

\section{CONCLUSION}

Chitosan was extracted from periwinkle shells, modified effectively by graft copolymerization of methyl methacrylate on to the maleilated chitosan and incorporated into the paint samples; the calculated Grafting efficiency (GE \%) of $75.3 \%$ and grafting yield (G $\%$ ) of $76.25 \%$ were obtained respectively. The FTIR spectra were highly instrumental in highlighting all the stages of the processes. The quadratic model outperformed the linear, 2FI and cubic models in explaining the viscometry behaviour of the formulation. The derived quadratic model can be effectively used to navigate through the design space (high and low viscosity). The
ANOVA results revealed that only the binder and solvent significantly affected the viscosity of the formulations. The RSM and ANN displayed high predictability of the response variable, however, ANN displayed higher superiority in capturing the experimental data.

\section{FUNDING STATEMENT}

This research work was supported by the Tertiary Education Trust Fund, Nigeria through Institution Based Research Grant (IBR). Years 2014-2015-2016 Merged Research Projects (RP) Intervention Funds, $9^{\text {th }}$ Batch. No 5. 


\section{REFERENCES}

[1] Ahmed, S. and Ikram, S. (2016). Chitosan based scaffolds and their applications in wound healing. Achievements in the Life Sciences, 10, 27-37.

[2] Akafuah, N. K., Poozesh, S., Salaimeh, A., Patrick, G., Lawler, K. and Saito, K. (2016). Evolution of the automotive body coating process - A review. Evolution of the automotive body coating process $-\mathrm{A}$ review. Coatings, 6(24), 1-22.

[3] Alireza, A., Rosiyah, Y., and Sengweon, G. (2009). Alkyd resins are still of major important binders in organic coatings. Malaysia Polymer International Conference. Malaysia.

[4] Asfaram, A., Ghaedi, M., Purkait, M.K., 2017. Novel synthesis of nanocomposite for the extraction of Sildenafil Citrate (Viagra) from water and urine samples: process screening and optimization. Ultrason. Sonochem. https://doi.org/10.1016/j.ultsonch.2017.03.045.

[5] Box, G.E.P., Hunter, J.S. and Hunter, W.G. (2005). Statistics for Experimenters: Design, Innovation, and Discovery, 2nd ed. NJ: Wiley-Interscience, Hoboken.

[6] Carneiro, J., Tedim, J., Fernandes, S. C. M., Freire, C. S. R., Silvestre, A. J. D., Gandini, A., Ferreira, M. G. S. and Zheludkevich, M. L. (2012). Chitosan-based self-healing protective coatings doped with cerium nitrate for corrosion protection of aluminum alloy 2024. Progress in organic coatings. $75,8-13$.

[7] Chen, Q., Xu, A., Li, Z., Wang, J. and Zhang, S. (2011). Influence of anionic structure on the dissolution of chitosan in 1-butyl-3methylimidazolium-based ionic liquids. Green Chemistry, 13(12). doi:10.1039/c/1gc15703e.

[8] Coates, J. (2000). Interpretation of Infrared Spectra: A practical approach. Encyclopedia of Analytical Chemistry. Chichester: John Wiley \& Sons.

[9] Desai, K. M., Survase, S. A., Saudagar, P. S., Lele., S. S. and Singhal, R S. (2008). Comparison of artificial neural network (ANN) and response surface methodology (RSM) in fermentation media optimization: Case study of fermentative production of scleroglucan. Biochemical Engineering Journal, 41, 266-273.

[10] Fettis, G. (2008). Automotive Paints and Coatings. WileyVCH: USA.

[11] Gianluca, C. and Salvatore, M. (2016). Applications of epoxy/thermoplastic blends. Switzerland: Springer International Publishing.

[12] Hemalatha, R. and Sudha, P. N. (2011). Synthesis and characterization of chitosan based graft co polymer: an efficient adsorbent for dyeing industry waste water. Elixir Appl. Chem. 40, 5504-5513.

[13] Husnugul, I. A., Leyal, E.D. and Erdal, C. (2013). Investigations of self-healing property of chitosanreinforced epoxy dye composite coatings. Journal of Materials, http://dx.doi.org/10.1155/2013/613717.
[14] IRchart (2021). Table of characteristic IR Absorptions. Retrieved from www.orgchembouler.com.

[15] Jamaluddin, M. F. R. (2015). Characteristic studies on types of paint spray for automotive parts in small and medium industry. Master of Mechanical Engineering Thesis, Universiti Tun Hussein Onn Malaysia.

[16] Jamil, M. S., Jones, F. R., Muhamad, N. N. and Makenan, S. M. (2015). Solid-state self-healing systems: The diffusion of healing agent for healing recovery. Sains Malaysiana, 44(6) 843-852.

[17] Jie Y., Panyue Z., Erhard H., Guangming Z., Yinan T., Johanna D. and Yang L. (2014). Comparison of Response Surface Methodology and Artificial Neural Network in Optimization and Prediction of Acid Activation of Bauxsol for Phosphorus Adsorption. Water Air Soil Pollut 225:2225, DOI 10.1007/s11270-014-2225-1

[18] Learner, T. (2000). A review of synthetic binding media in twentieth-century paints. Conservator, 24, 96-103.

[19] Lohbeck, K. and Haferkorn, H. (2000). Maleic and Fumaric Acids. Ullmann's Encyclopedia of Industrial Chemistry $7^{\text {th }}$ ed. (1999-2014). NY, NY: John Wiley \& Sons.

[20] Merc (2021). IR spectrum Table and chart. Retrieved from www.sigmaaldrich.com.

[21] Michael, D.T Clark (2005). X-polymer-D-paint and pigment. Retrieved from http://www.paintquality.com/media_centre/paint publications/edu/module.pdf

[22] Okoya, A. A., Akinyele, A. B., Ofoezie, I. E., Amuda, O. S., Alayande, O. S. and Makinde, O. W. (2014). Adsorption of heavy metal ions onto chitosan grafted cocoa husk char. African Journal of Pure and Applied Chemistry, 8(10), 147151.

[23] Okoye, C. C., Onukwuli, O. D. and Okey-Onyesolu, C. F. (2019). Predictive capability evaluation of RSM and ANN models in adsorptive treatment of crystal violet dye simulated wastewater using activated carbon prepared from Raphia hookeri seeds. Journal of the Chinese Advanced Materials Society, 6(4), 478-496.

[24] Pilkington, J. L., Preston, C. and Gomes, R. L. (2014). Comparison of response surface methodology (RSM) and artificial neural networks (ANN) towards efficient extraction of artemisinin from Artemisia annua. Industrial crops and products, 58, 15-24.

[25] Rodger, T. (2008). Paint technology handbook. CRC press Tailor and Francis group. Boca Raton, London. PP. 79 and 221-222.

[26] Schoff, C. (2021). Optimum viscosity for paint application. American Coatings Association. Retrieved from www.paint.org.

[27] Standeven, H. (2006). The Development of Decorative Gloss Paints in Britain and the United States C. 1910-1960. Journal of the American Institute for Conservation, 45, 5165 . 
[28] Uzoh, C. F. and Onukwuli, O. D.(2014). Characterization, kinetics and statistical screening analysis of gmelina seed oil extraction process. Mater. Renew. Sustain. Energy, 38 (3), 1e12. https://doi.org/10.1007/s40243-014-0038-1.

[29] Van der Weerd, J., Heeren R. M. A and Boon, J. J. (2004). Preparation methods and accessories for the infrared spectroscopic analysis of multi-layer paint . Stud Conserv. 49, 193-210.

[30] Yolmeh, M., Habibi Najafi, M. B. and Farhoosh, R. (2014). Optimization of ultrasound-assisted extraction of natural pigment from annatto seeds by response surface methodology (RSM). Food Chem, 155, 319-324.

[31] Younes, I. and Rinaudo, M. (2015). Chitin and Chitosan Preparation from Marine Sources. Structure, Properties and Applications. Mar. Drugs, 13, 1133-1174. 